\title{
SOME EPIDEMIOLOGICAL INDICATORS CHARACTERIZING THE SPREAD OF HEPATITIS A IN THE REGION OF STARA ZAGORA
}

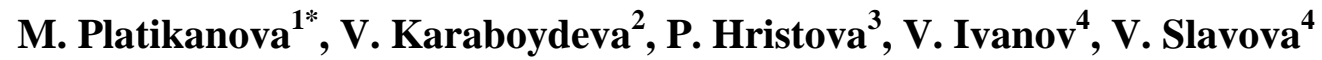 \\ ${ }^{1}$ Department "Hygiene, Infectious Diseases and Epidemiology", Medical Faculty, Trakia University, \\ Stara Zagora, Bulgaria \\ ${ }^{2}$ Regional Health Inspection, Stara Zagora, Bulgaria \\ ${ }^{3}$ Medical Faculty- student, Trakia University, Stara Zagora, Bulgaria \\ ${ }^{4}$ Department of Neurology, Psychiatry and MDS, Medical Faculty, Trakia University, \\ Stara Zagora, Bulgaria
}

\begin{abstract}
Introduction: Viral hepatitis A is a widespread infectious disease with a faecal-oral mechanism of transmission of the infection. Together with other food-borne and water-borne infectious diseases, it is a global health problem.

Aim: To analyze some epidemiological indicators characterizing the prevalence of hepatitis A in the region of Stara Zagora for the period 2014-2016.

Material and methods: Annual reports of the Regional Health Inspection - Stara Zagora for registered cases of infectious diseases (statistical documentation - Form 3 - 85 approved by the Ministry of Health), acute infectious diseases analyzes in Bulgaria of National Center of Infectious and Parasitic Diseases and official statistical information of National Center of Public Health and Analyses.

Results: Viral hepatitis registered for the period is laboratory confirmed. The spread of the infected by gender shows a higher proportion of men - 54.81\% (336 units), compared with the infected women (45.19\%, 227 cases). The highest incidence of Acute Viral hepatitis A is registered in the most risky and susceptible to intestinal infections age groups - early childhood and school age. The incidence of Viral hepatitis type A in the region of Stara Zagora in 2016 is above the average for the country, unlike the previous two years. Three outbreaks of hepatitis A (2 in 2015 and 1 in 2016) were reported.

Conclusion: Prophylaxis and prevention are crucial to reducing morbidity, as the disease affects human health and life and also leads to economic losses. This requires increased public awareness of viral hepatitis A, enhancing the population's health culture, personal hygiene, and strict control over nutrition and water supply in settlements.
\end{abstract}

Key words: hepatitis A, epidemiological indicators, morbidity

\section{INTRODUCTION}

Viral hepatitis type A is a widespread acute infectious disease with a faecal-oral transmission of the infection and it is characterized by liver parenchyma damage and jaundice. Together with other infectious diseases transmitted mainly with food and water, it is a global health problem (1). The source of the infection is the sick person. The virus is emitted by the feces, urine and saliva of the sick person. It is spread sporadically and epidemically $(2,3,4)$.

\footnotetext{
*Correspondence to: Magdalena Platikanova, 11 Armeyska Str, 6000 Stara Zagora, Bulgaria, Phone:, +35942664240, E-mail: mplatikanova@abv.bg
}

\section{OBJECTIVE AND TASKS}

The purpose of this study is to analyze some epidemiological indicators characterizing the prevalence of viral hepatitis $A$ in the region of Stara Zagora for the period 2014-2016.

\section{MATERIALS AND METHODS}

Annual reports of the Regional Health Inspectorate - Stara Zagora for the registered cases of infectious diseases (statistical documentation - Form 3 - 85 approved by the Ministry of Health), analyzes of acute infectious diseases in Bulgaria of the National Center for Infectious and Parasitic Diseases and official statistical information of the National Center for Public Health and Analyzes are used (5-8). 
RESULTS AND DISCUSSION

For 2014-2016, 613 cases of acute viral hepatitis A were registered in the territory of the region of Stara Zagora. The relative share of cases of this type of hepatitis in the structure of the infectious pathology in the region of Stara Zagora is respectively: $3.41 \%$ - in 2014, $16.40 \%$ - in 2015; 5.78\% - in 2016. (Figure 1).

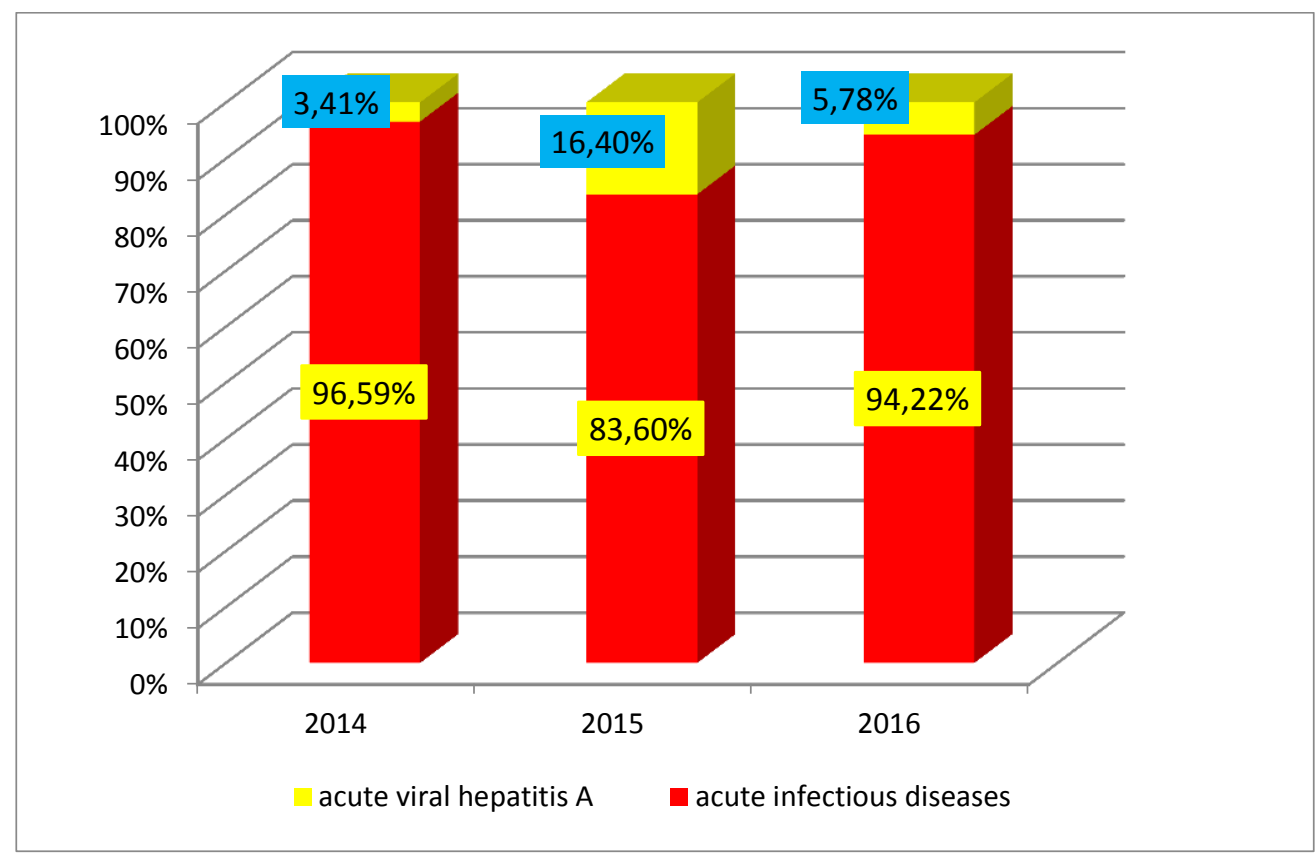

Figure 1. Relative share of acute viral hepatitis A in the structure of the common morbidity for the period 2014-2016

Compared with other hepatitis, its spread is the greatest (Figure 2).

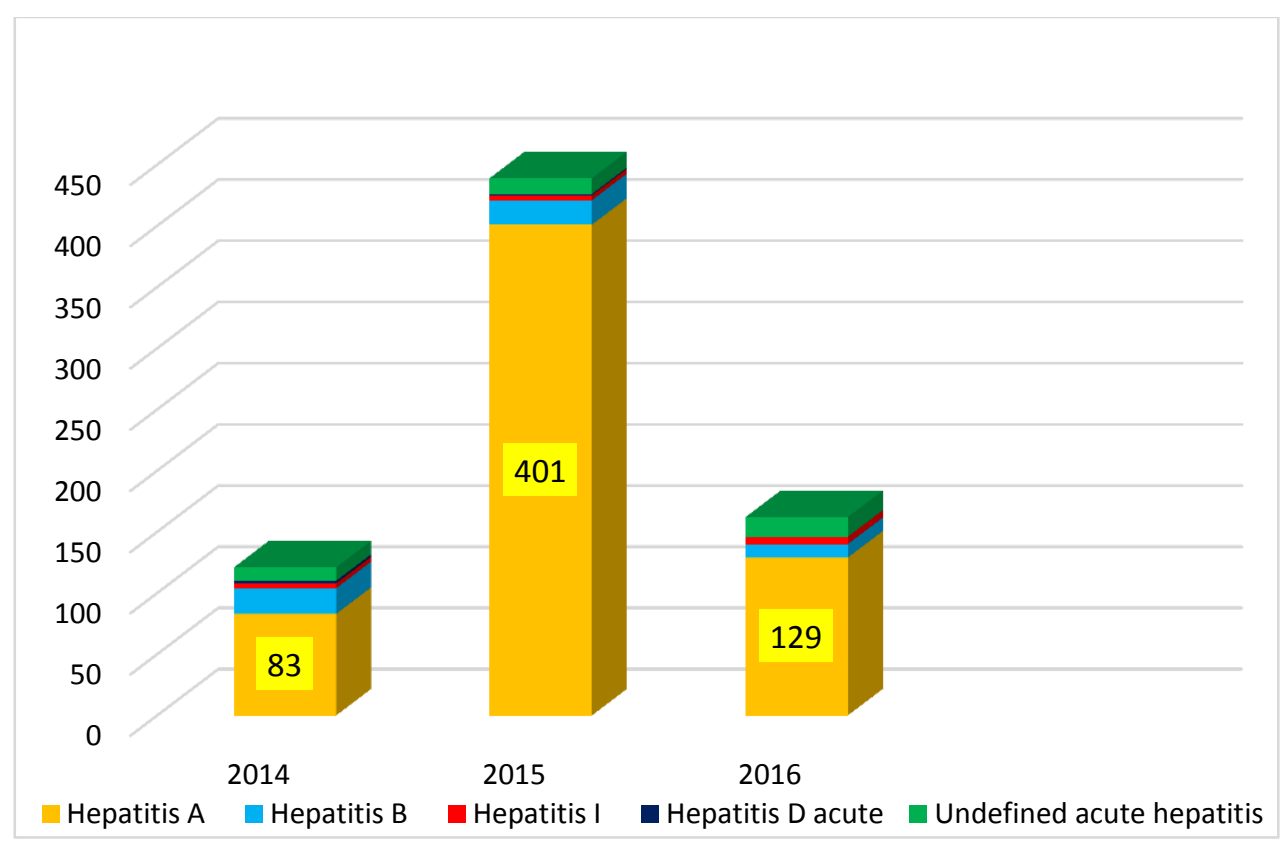

Figure 2. Acute viral hepatitis A in the virus hepatitis group

The gender distribution of acute viral hepatitis A among patients shows a higher relative share of sick men - 54.26\% (336 cases), compared with female patients $(45.19 \%$ - 277 cases $)$ (Figure 3). 


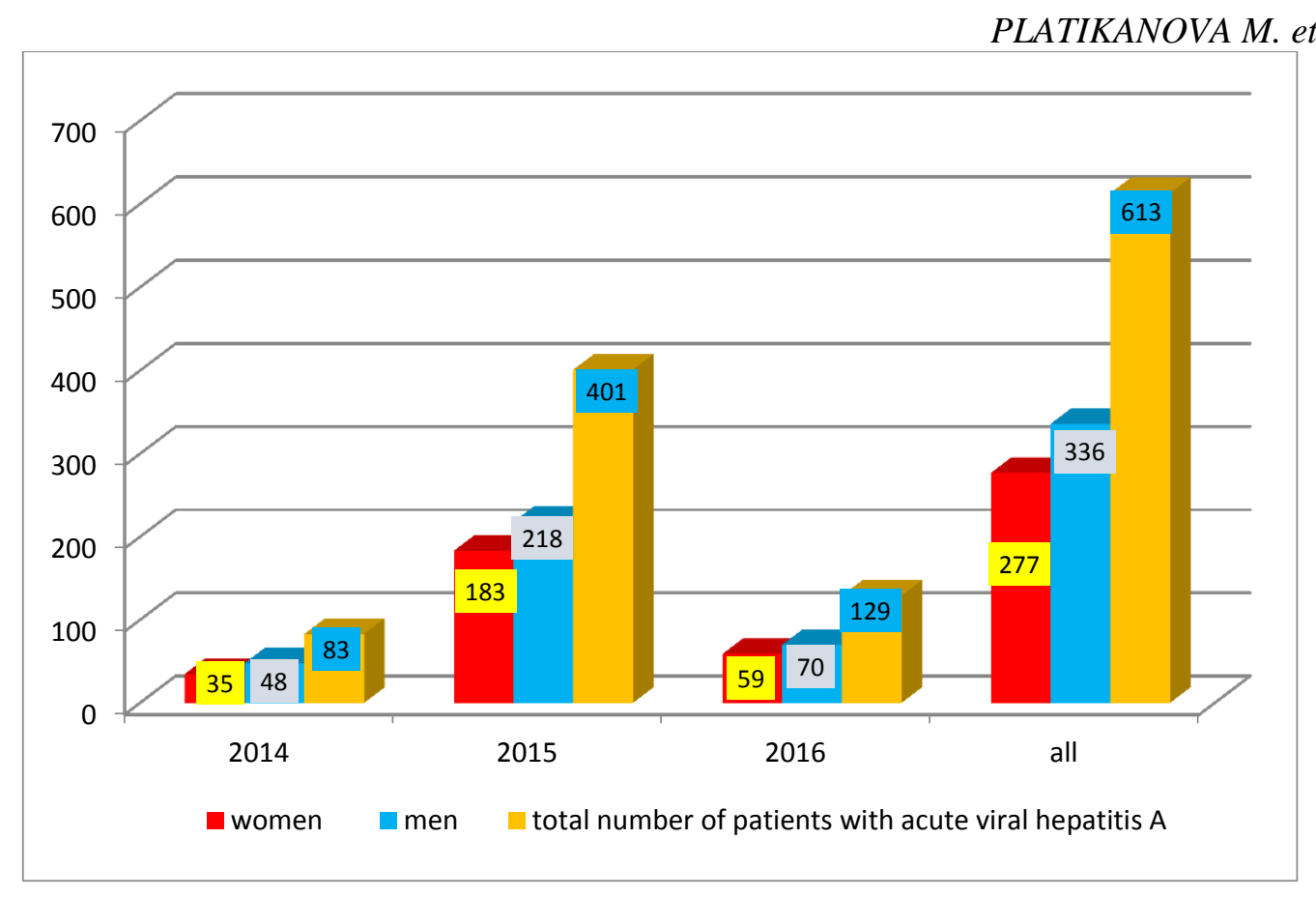

Figure 3. Distribution of people with acute viral hepatitis A for the period 2014-2016 by gender

Our result confirms a number of studies worldwide. The prevalence of hepatitis A in the United States in 2006 was higher in men than in women, as in the late 1990s the number of men with acute viral hepatitis A was about twice as higher as women. However, since 2001 the rate has been decreasing and in 2003 the ratio of the number of diseased men to women varies from 1.2 to 1.3 . In 2006, the overall incidence in men was 1.3 cases per 100,000 population and 1.1 cases per 100,000 population among women. According to the study, the difference in hepatitis A by sex rates is mostly expressed in those aged $30-49$ years $(9,10,11)$.

During the observed period, all age groups in the region of Stara Zagora were affected, with highest incidence of acute viral hepatitis $\mathrm{A}$ in the age group 5 to 9 years, followed by the age group 0 to 4 years old and the group of 10-14 year olds. In the nursing age, one case was registered for 2015. The lower incidence of acute viral hepatitis A after 40 years of age can be explained the level of immunity tension as well as the high rate of asymptomatic infection in individuals over the age of 50 years (Figure 4).

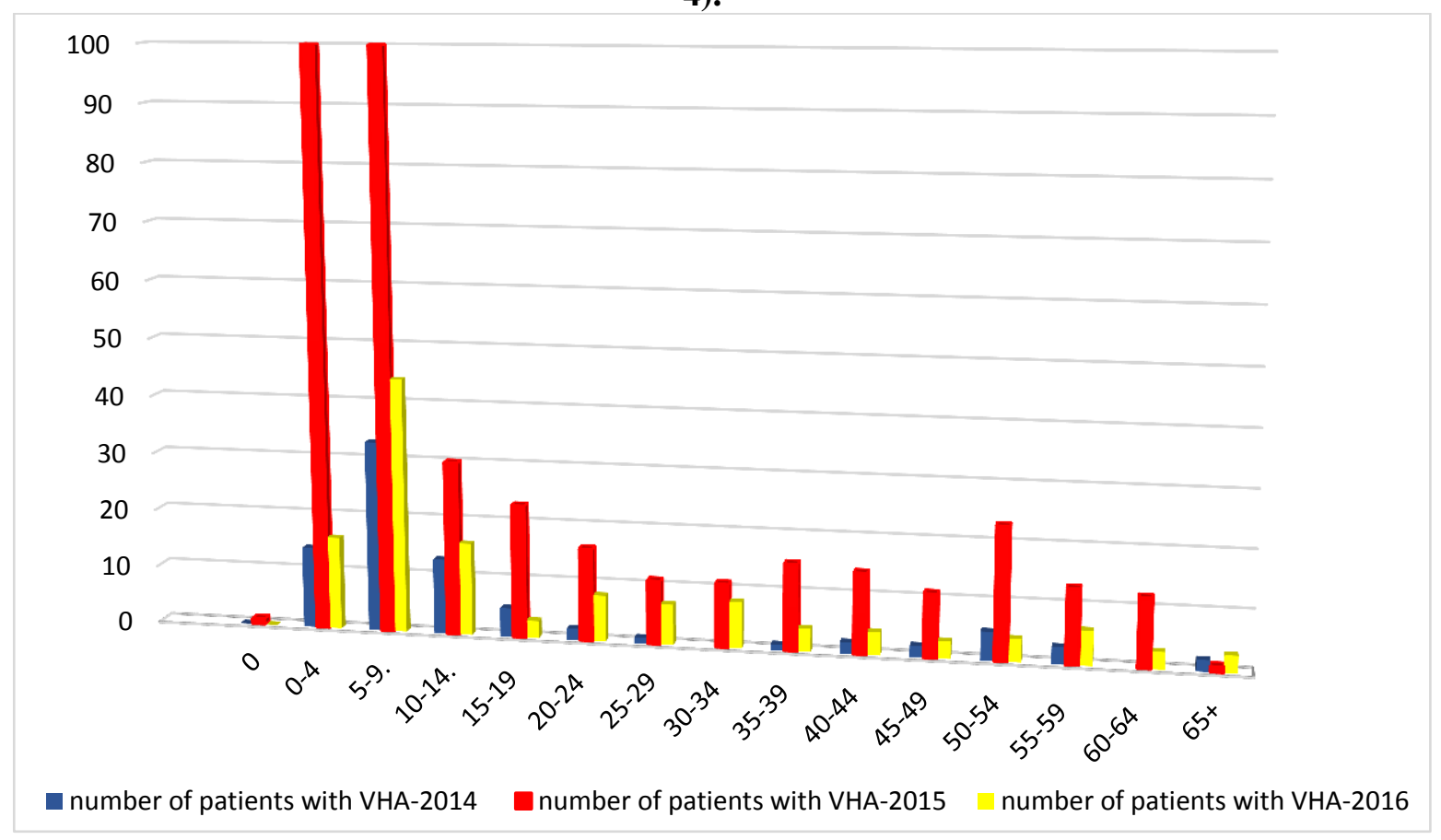

Figure 4. The spred of people with acute viral hepatitis A for the period 2014-2016 by age 
Similar results of a small relative incidence of acute viral hepatitis A among adults over the age of 40 years have been found in US studies. A research has shown that since the last outbreak at national level in 1995, cases of the disease have declined among all age groups, but the most significant is the decrease among children. Historically, childhood morbidity was the highest. Due to the overall reduction in hepatitis A cases in 2006, the percentages are similar for all age groups ranging from 0.7 cases per 100,000 population among children aged $<5$ years to 1.4 cases per 100,000 population in the age 5 to 14 years $(11,12)$.

Calculated morbidity for 2014-2016 in the region of Stara Zagora shows that the number of cases of acute viral hepatitis A reported in 2014 was 83 (morbidity 25.16\%000), in 2015. the patients were 401 (morbidity 122.21\%000); and in 2016 registered cases were 129 (morbidity 40.14\%000) (Figure 5).

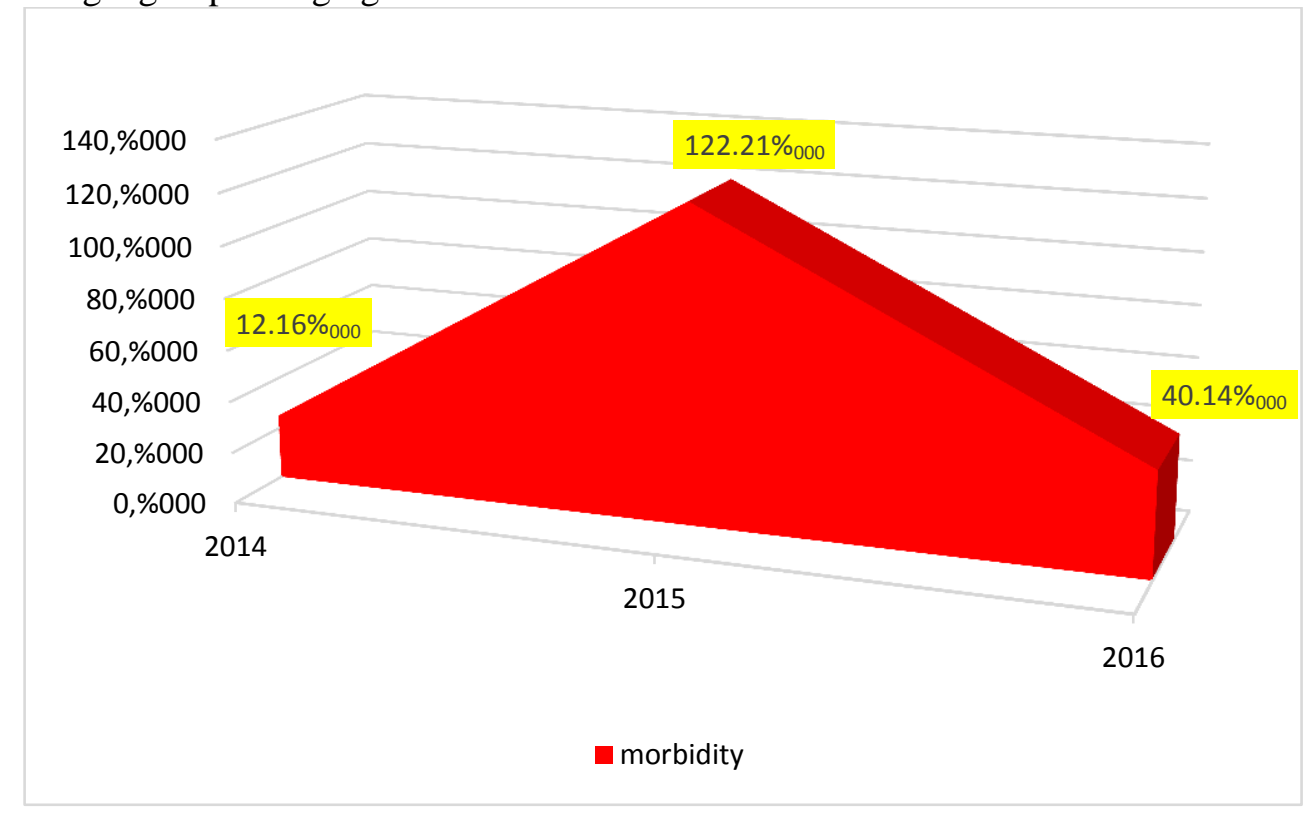

Figure 5. Viral hepatitis A morbidity for the period 2014-2016

The significantly higher value of the indicator compared to the one in the country in 2015. (1.95\% relative share of registered cases of acute viral hepatitis A in the country for 2015 and $16.40 \%$ for the region of Stara Zagora) is due to the two epidemic outbreaks that occurred during the year. In the same year there was one died patient in the age group of 50-54 years (7). Epidemiological studies show that the outbreaks occur and spread mainly among the Roma population living in poor living conditions with poor sanitary and hygienic status, as well as in organized children and student collectives.

Acute viral hepatitis A takes an important place in the structure of infectious pathology both in Bulgaria and abroad. It is one of the most common diseases for the United States for the period 1987-1997, as 28,000 cases per year are registered in the country. This raises the need from prophylaxis and prevention of the disease, involving the use of effective vaccines available in the United States since 1995. They enable public health authorities to significantly reduce the spread of the disease and eliminate it $(13,14,15)$.
Immunoprophylaxis, good tolerance and effectiveness of vaccines, their ability to protect the body from infection over a long period of time determine their application in Bulgaria. The application of this specific prophylaxis, the implementation of quarantine and anti-epidemic measures in the case of registered hepatitis A are part of the prevention of the disease.

\section{CONCLUSIONS}

In the region of Stara Zagora the highest incidence of acute viral hepatitis A was registered among the risk age groups susceptible to intestinal infections - early childhood and school age. In the organized children and school teams the contact-way is leading to the transmission of the infection. Epidemic outbreaks of acute viral hepatitis A are formed in environment with poor sanitation and hygiene habits and health culture.

Prophylaxis and prevention are extremely important in reducing acute viral hepatitis A morbidity. This requires increasing the public awareness, enhancing the population's health culture for strict personal hygiene, public sanitary and hygienic standards, and strict 
control over nutrition and water supply in settlements.

\section{REFERENCES}

1. Action Plan of the National Reference Center for Food and Water infections in 2018

https://www.ncipd.org/images/UserFiles/Fil e/NRC_plans/5.\%20Infekcii\%20s\%20hrani $\%$ 20i\% 20vodi.pdf

2. Banerjee, I., Gladstone B. P., IturrizaGomara, M., Gray, J. J., Brown, D. W., Kang G., Evidence of intrafamilial transmission of rotavirus in a birth cohort in South India. J Med Virol, 80 (10):18581863,2008

3. Bell, B. P., Kruszon-Moran, D., Shapiro, C. N., Lambert, S. B., McQuillanb, G. M., Margolisa H. S., Hepatitis A virus infection in the United States: serologic results from the Third National Health and Nutrition Examination Survey. Vaccine, 23:57985806, 2005.

4. WHO, Weekly epidemiological

5. Kozhuharova, M., Kurchatova, A., Marinova, L., Vladimirova, N., Georgieva, T., Stefanova, V., Parmakova, K., Minkova, A., Parmakova, K., Acute Infectious Diseases in Bulgaria in 2014 (Key Epidemiological Indicators)

http://www.ncipd.org/index.php?option=co m_docman\&view=list\&slug=2014\&Itemid $=1127 \&$ lang $=$ en

6. Kurchatova, A., Vladimirova, T., Minkova, A., Parmakova, K., Acute Infectious Diseases in Bulgaria in 2016. (Basic Epidemiological Indicators)

http://www.ncipd.org/index.php?option=co $\mathrm{m} \_$docman\&view $=$download\&alias $=121$ analiz-cd-balgariya-

$2016 \&$ category_slug $=2016 \&$ Itemid $=1127 \&$ lang=en

7. Marinova, L., Kurchatova, A., Vladimirova, N., Georgieva, T., Minkova, A., Parmakova, K., Acute Infectious Diseases
PLATIKANOVA M. et al. in Bulgaria in 2015 (Basic Epidemiological Indicators)

http://www.ncipd.org/index.php?option=co m_docman\&view=document\&layout=defa ult\&alias=79-analiz-cd-balgariya2015\&category_slug $=2015$ $1 \&$ Itemid $=1127 \&$ lang $=$ en

8. Ordinance No 21 of 18 July 2005 on the Procedure for Registration and Reporting of Contagious Diseases, Am. SG. No. 52 of 8 July 2011

9. Abstracts of the Infectious Diseases Society of America 41st Annual Meeting, San Diego, California, October 9-12, 2003. Alexandria, VA: Infectious Diseases Society of America, 2003.

10.Doyle, T. J., Glynn, M. K., Groseclose, S. L., Completeness of notifiable infectious disease reporting in the United States: an analytical literature review. Am $J$ Epidemiol, 155(9):866-874,

11.Wasley, A., Grytdal, S., Gallagher, K., Surveillance for Acute Viral Hepatitis United States, 2006. MMWR, 57 (SS02):126, 2008.

12.Bialek, S. R., Thoroughman, D. A., Hu, D., Simard, E. P., Chattin, J., Cheek, J., Bell, B. P., Hepatitis A incidence and hepatitis A vaccination among American Indians and Alaska Natives, 1990-2001. Am J Public Health, 94:996-1001, 2004.

13.Armstrong, G. L., Bell, B.P., Hepatitis A virus infections in the United States: modelbased estimates and implications for childhood immunization. Pediatrics, 109(5):839-845, 2002.

14.Centers for Disease Control and Prevention. Prevention of Hepatitis A Through Active or Passive Immunization: Recommendations of the Advisory Committee on Immunization Practices, MMWR, 45 (RR-15), 1-30, 1996.

15.Wasley, A., Samandari, T., Bell, B.P., Incidence of hepatitis A in the United States in the era of vaccination. JAMA, 294:194201, 2005. 